\title{
Influence of some experimental variables and matrix components in the determination of antioxidant properties by $\beta$-carotene bleaching assay: experiments with BHT used as standard antioxidant
}

\author{
Andrzej L. Dawidowicz $\cdot$ Małgorzata Olszowy
}

Received: 20 April 2010/Revised: 30 June 2010/Accepted: 12 July 2010/Published online: 25 July 2010

(C) The Author(s) 2010. This article is published with open access at Springerlink.com

\begin{abstract}
The $\beta$-carotene bleaching assay belongs to the oldest and continuously commonly applied methods of estimating the antioxidant activity of compounds and mixtures. In this method, the antioxidant activity of the examined substance is evaluated by the spectrophotometric measurement of $\beta$-carotene concentration changes in $\beta$ carotene/peroxyl radicals $\left(\mathrm{LOO}^{\circ}\right)$ systems with and without antioxidant. Yet a little is known about factors influencing the value of inhibition percent of the investigated antioxidant, estimated by this method. The paper shows that both the antioxidant solvent type and the amount of the antioxidant solvent in the measuring system significantly influence the inhibition percent value for butylohydroxytoluene (BHT), used as standard antioxidant in the performed experiments. Moreover, the results shown in the paper prove the essential influence of hydrogen and metal ions on the results of antioxidant assay. The relationships discussed in this paper indicate the necessity of standardizing $\beta$-carotene method and reveal the complexity of the problem of estimation of adequate antioxidant activity of examined substances.
\end{abstract}

Keywords Antioxidant properties $\cdot \beta$-Carotene bleaching assay $\cdot$ Butylohydroxytoluene $($ BHT) $\cdot$ Free radical

\section{Introduction}

Currently known negative action of radicals on humans and animals [1-4] implicates more and more interest in research

\footnotetext{
A. L. Dawidowicz $(\bowtie) \cdot$ M. Olszowy

Faculty of Chemistry, Maria Curie Sklodowska University, Pl. Marii Curie Sklodowskiej 3, 20-031 Lublin, Poland e-mail: dawid@poczta.umcs.lublin.pl
}

concerning antioxidant properties of substances, which prevent living organisms from the damaging influence of these reactive species. $\beta$-carotene bleaching assay is one of the most popular methods applied for the estimation of antioxidant activity of examined substances and extracts. In this method, the antioxidant activity is determined by comparing two competitive chemical reactions in which the examined antioxidant and/or model antioxidant, $\beta$-carotene, take part [5]. $\beta$-carotene/linoleic acid emulsion in water with generated peroxyl radicals $\left(\mathrm{LOO}^{\circ}\right)$ is the main component of the reaction medium. The changes of $\beta$-carotene concentration in a control sample and in a sample containing an examined antioxidant are monitored during the assay. $\beta$ carotene reacts with peroxyl radicals in sample just after the depletion of the investigated antioxidant. The loss of $\beta$-carotene is measured spectrophotometrically at $470 \mathrm{~nm}$. Antioxidant properties of the examined compounds are evaluated from kinetics curves (absorbance vs. time) for the sample and the control. In this method, antioxidant activity (AA) is most frequently expressed as \% inhibition relative to the control, which is free of the examined antioxidant.

As results from the literature [6-9], different volume ratios of the examined antioxidant solution to $\beta$-carotene/linoleic acid emulsion are used during antioxidant activity assay. Moreover, the $\beta$-carotene bleaching assay is applied in comparing the antioxidant activities of the examined extracts, for example of the same plant material, differing not only in the qualitative and quantitative composition but also in the type of extracting solvent, which is the main extract component. In the context of these differences, the question appears whether the type and the amount of the antioxidant solvent in the measuring system influence the estimation of antioxidant activity. Moreover, even the same plant contains components which do not exhibit antioxidant activity, such as metal ions or acids, and which can exist in examined plants in different 
amounts. The presence of all these factors makes the estimation of their influence on the antioxidant properties of extracts worthwhile.

The paper discusses the effect of the antioxidant solvent type, of its amount in the measuring system, and of the concentration of chosen metal ions and $\mathrm{pH}$ on the antioxidant activity of butylohydroxytoluene (BHT), treated here as standard antioxidant, estimated by $\beta$-carotene bleaching assay. The presented problem should be considered in wider context, dealing with the influence of the mentioned experimental variable and matrix components on the estimation of true antioxidant properties of food components, plant extracts and antioxidants applied for food preservative.

\section{Experimental}

\section{Reagents}

Methanol, ethanol, propanol, acetone, dioxane, chloroform, phosphoric acid, monobasic sodium monophosphate, $\mathrm{CuCl}_{2} \times 9 \mathrm{H}_{2} \mathrm{O}$ and $\mathrm{Fe}_{2}\left(\mathrm{SO}_{4}\right)_{3} \times 5 \mathrm{H}_{2} \mathrm{O}, \mathrm{Zn}\left(\mathrm{NO}_{3}\right)_{2} \times$ $5 \mathrm{H}_{2} \mathrm{O}$ (all of analytical-reagent grade) were purchased from the Polish Chemical Plant-POCh (Gliwice, Poland). $\beta$-carotene, butylohydroxytoluene (BHT), linoleic acid and Tween 20 were purchased from Sigma-Aldrich (Poznań, Poland). Water was purified on a Milli-Q system from Millipore (Millipore, Bedford, MA, USA).

\section{Methods}

The systems with the same amount of BHT were used for the investigation into solvent type influence on $\mathrm{LOO} \% \beta$-carotene reaction kinetics. The estimation of the reacted $\beta$-carotene concentration in the examined systems was performed by the slightly modified Dapkevicius method [10]. The stock solution of $\beta$-carotene/linoleic acid emulsion in water was prepared as follows: the mixture composed of $25 \mu \mathrm{L}$ of linoleic acid, $185 \mu \mathrm{L}$ of Tween $20(200 \mathrm{mg})$ and $1 \mathrm{~mL}$ of $\beta$-carotene solution (containing $0.5 \mathrm{mg}$ of $\beta$-carotene in $1 \mathrm{~mL}$ of chloroform) underwent the vacuum evaporation process to remove chloroform. The obtained residue was next dispersed in $100 \mathrm{~mL}$ of distilled water saturated with oxygen $(30 \mathrm{~min}$ at $100 \mathrm{~mL} / \mathrm{min}$ ) and vigorously shaken. The absorbance of the final emulsion was measured at $470 \mathrm{~nm}$ using UV Probe-1800 spectrophotometer (Shimadzu, Japan). As a blank, emulsion without $\beta$-carotene was applied in measurements.

\section{Influence of antioxidant solvent type on the inhibition percent}

Aliquot $(2.5 \mathrm{~mL})$ of the emulsion with $\beta$-carotene was placed in a glass optical cuvette $(1 \mathrm{~cm} \times 1 \mathrm{~cm} \times 3.5 \mathrm{~cm})$ containing $350 \mu \mathrm{L}$ of BHT solution $(c=0.005 \mathrm{mg} / \mathrm{mL})$ in appropriate solvent, stoppered tightly, mixed well and placed in a water bath at $45^{\circ} \mathrm{C}$. Methanol, ethanol, npropanol, acetone and dioxane were used as BHT solvents. The zero reading for the reaction mixture was taken at $470 \mathrm{~nm}$ immediately after the mixing. Subsequent readings were taken at regular intervals $(10 \mathrm{~min})$ until carotene in the control sample was decolorized (180 min). The control sample was prepared in the same way as the reacting mixture. The replacement of the BHT solution in a given solvent by pure solvent was the only difference.

Emulsion without $\beta$-carotene $(2.5 \mathrm{~mL})$ mixed with $350 \mu \mathrm{L}$ pure solvents (solvent employed for BHT dissolution in the experiment) was used to zero spectrophotometer.

The antioxidant activity was expressed as inhibition percentage relative to the control using the following equation:

$\mathrm{AA}=100 \cdot \frac{\mathrm{DR}_{\mathrm{C}}-\mathrm{DR}_{\mathrm{S}}}{\mathrm{DR}_{\mathrm{C}}}$

where AA - antioxidant activity, $\mathrm{DR}_{\mathrm{C}}$-degradation rate of $\beta$-carotene in the control sample $=\{[\ln (a / b)] / t\}, \mathrm{DR}_{\mathrm{S}}-$ degradation rate of $\beta$-carotene in the sample with antioxidant $=\{[\ln (a / b)] / t\}, a=$ absorbance at time $=0, b=$ absorbance at defined time (for example at $10,20, \ldots$, to $180 \mathrm{~min}), t=$ time.

Influence of antioxidant solvent volume on the inhibition percent

$\beta$-Carotene emulsion $(2.5 \mathrm{~mL})$ was mixed in a $4-\mathrm{mL}$ test tube with methanolic BHT solution $(50 \mu \mathrm{L})(c=0.035$ $\mathrm{mg} / \mathrm{mL}$ ) and supplemented with a proper amount of methanol and water up to 3 -mL volume. Table 1 contains the exact compositions of the examined systems. The system formation presented in the table allows to obtain reagent mixtures differing in methanol/water ratio, guarantees the same amount of the antioxidant in the measuring systems and saves the chemical reagents (there is no need to prepare antioxidant solutions in each solvent).

The percent of inhibition was estimated following the procedure described previously.

\section{Influence of $\mathrm{pH}$ on the inhibition percent}

$\beta$-Carotene emulsion $(2.5 \mathrm{~mL})$ was mixed in a $4-\mathrm{mL}$ test tube with methanolic BHT solution $(50 \mu \mathrm{L}),(c=0.035$ $\mathrm{mg} / \mathrm{mL})$, water $(400 \mu \mathrm{L})$ and phosphoric buffer $(50 \mu \mathrm{L})$. Phosphoric buffers of the following $\mathrm{pH}$ were used: 1.66; $3.65 ; 4.15 ; 5.50$; and 6.67. In these experiments, the control was composed of $\beta$-carotene emulsion $(2.5 \mathrm{~mL})$, water $(450 \mu \mathrm{L})$ and methanol $(50 \mu \mathrm{L})$. The antioxidant activity was estimated according to the assay described previously. 
Table 1 Volumes (in $[\mu \mathrm{L}]$ ) of the individual components used for the formation of the examined systems

\begin{tabular}{lrrrrr}
\hline System component & \multicolumn{7}{l}{ System number } \\
\cline { 2 - 7 } & 1 & 2 & 3 & 4 & 5 \\
\hline$\beta$-carotene/linoleic acid emulsion & 2,500 & 2,500 & 2,500 & 2,500 & 2,500 \\
BHT in methanol & 50 & 50 & 50 & 50 & 50 \\
Methanol & - & 50 & 150 & 250 & 450 \\
Water & 450 & 400 & 300 & 200 & - \\
Total volume & 3,000 & & & & \\
\hline
\end{tabular}

\section{Influence of metal content on the inhibition percent}

$\beta$-Carotene emulsion $(2.5 \mathrm{~mL})$ was mixed in a 4-mL test tube with methanolic BHT solution $(50 \mu \mathrm{L})(c=0.035 \mathrm{mg} / \mathrm{mL})$, water $(400 \mu \mathrm{L})$ and metal ion solution in water $(50 \mu \mathrm{L})$. The following ion solutions were used: $\mathrm{Cu}(\mathrm{II})$ at concentration $1.0 \times 10^{-4} ; 5.0 \times 10^{-4}$ and $30 \times 10^{-4} \mathrm{mg} / \mathrm{mL} ; \mathrm{Fe}($ III) at concentration $0.1 \times 10^{-3} ; 1.0 \times 10^{-3} ; 14.0 \times 10^{-3}$ and $22.0 \times 10^{-3}$ and $\mathrm{Zn}(\mathrm{II})$ at concentration $2.0 \times 10^{-4}$; $8.0 \times 10^{-4}$ and $20.0 \times 10^{-4} \mathrm{mg} / \mathrm{mL}$. The control was composed of $\beta$-carotene emulsion $(2.5 \mathrm{~mL})$, water $(450 \mu \mathrm{L})$ and methanol $(50 \mu \mathrm{L})$. The $\%$ of inhibition was estimated following the procedure described earlier.

\section{Results and discussion}

Figure 1 shows percent of inhibition of the sample in relation to the control during $180 \mathrm{~min}$ of the reaction for systems differing in the type of the applied antioxidant solvent. It should be stressed that the systems contained the same amounts of the reagents and solvents-see "Experimental". As results from the obtained relationships, the plotted percent of inhibition curves (the established BHT antioxidant activity) are different and depend on the antioxidant solvent type. BHT exhibits higher antioxidant activity in its methanolic and acetonic solutions, whereas its activity in dioxane is significantly lower. $\beta$-Carotene scavenging properties are due to the formation of a radical adduct $\left[\beta\right.$-car-OOR $\left.{ }^{\bullet}\right]$. The adduct formation occurs at the absence of a stronger antioxidant than $\beta$-carotene and is not expected to be affected by solvent changes [11, 12]. The presented results prove that the solvent type influences the estimation of antioxidant activity of BHT.

A few reasons can be responsible for the observed phenomenon. The reaction mechanism between phenolic antioxidant (BHT) and peroxyl radical in $\beta$-carotene method is historically believed to be an H-atom transfer (HAT) mechanism but has recently been revised to a proton-coupled electron transfer (PCET). In this mechanism, complex formation between the phenol and peroxyl radical

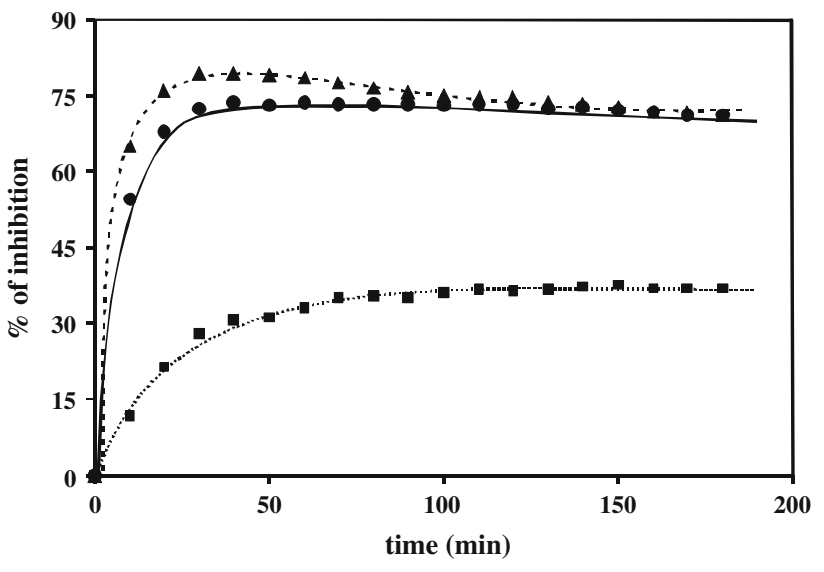

Fig. 1 The influence of BHT solvent type on antioxidant activity percent of BHT determined by $\beta$-carotene bleaching test during 180 min of the reaction. Dashed line with triangles represents BHT dissolved in acetone; solid line with circles and dotted line with squares correspond to BHT dissolved in methanol and 1,4-dioxane, respectively. For details concerning measuring system compositions, see "Experimental"

precedes the reaction, whereby the phenolic hydrogen is $\mathrm{H}$ bonded to the peroxyl radical. This hydrogen is then moved as a proton from the phenol to the ion pair on the peroxyl radical along with the coupled movement of an electron from the $2 p$ ion pair of the phenolic oxygen to the orbital containing the unpaired electron on the peroxyl radical, such that the electron travels between two formally nonbonding orbitals [13]. As results from the literature [14], the solvent type influences the hydrogen transfer kinetics. Dioxane, due to its basic character, is a strong proton acceptor $[15,16]$ and can slow down the reaction velocity. This may explain the lower value of BHT inhibition percent in dioxane.

As the system used for antioxidant activity assay by the $\beta$-carotene method contains $\beta$-carotene/linoleic acid water emulsion, the antioxidant solvent type, due to its different hydrophobicity, may influence the dispersion (or solubility) of the emulsion or of its components and, in consequence, may change the reaction velocity. According to the literature [17], the dispersion component $\left(\delta_{\mathrm{d}}\right)$ of total solubility parameters, which can be assumed as a measure of hydrophobic interaction ability, is the highest for dioxane (19.0), while methanol and acetone have smaller hydrophobicity ( $\delta_{\mathrm{d}}$ equal 15.1 and 15.5 , respectively). It is difficult to arbitrate at this moment which explanation is more probable because analogous changes in the BHT antioxidant activity are observed in systems containing methanol or ethanol or propanol as antioxidant solvents-see Fig. 2. Further complication is the fact that solvents differ both in their acidic properties (acidic character diminishes from methanol to propanol) and in their hydrophobic character ( $\delta_{\mathrm{d}}$ equal $15.1 ; 15.8$ and 16.0 , respectively). 


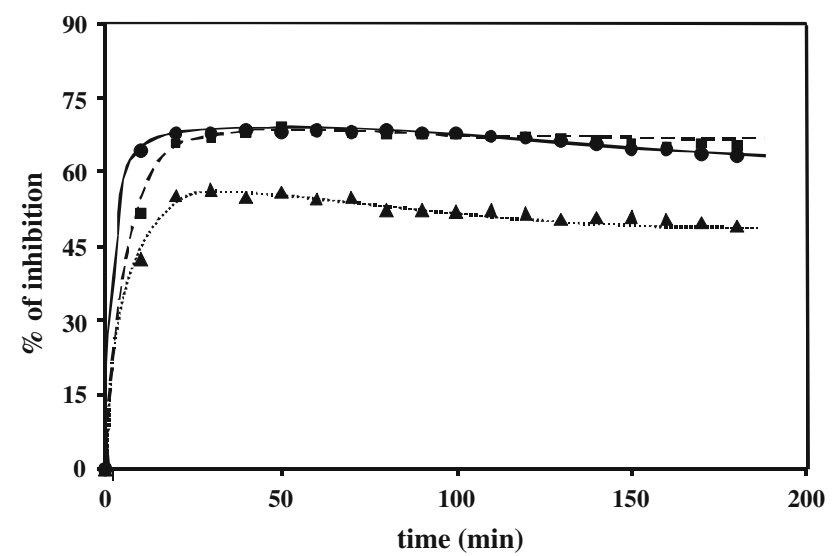

Fig. 2 The influence of BHT solvent type on antioxidant activity percent of BHT determined by $\beta$-carotene bleaching test during 180 min of the reaction. Methanol-solid line with circles; ethanoldashed line with squares; and propanol-dotted line with triangles

The observed discrepancies in the estimation of BHT antioxidant activity may also be connected with different surface tension in the applied measuring systems.

Whatever the true explanation of the different inhibition percent values is, our experiments prove the essential influence of the antioxidant solvent type on the estimation of antioxidant activity of the examined compound.

As it was mentioned in Introduction, researches frequently employ different volume ratios of the examined antioxidant solution to $\beta$-carotene/linoleic acid emulsion when estimating the antioxidant activity. Figure 3 shows the inhibition percent of the sample in relation to the control after 180 min of the reaction versus BHT solvent volume (methanol) expressed in percent. It should be stressed that all measuring systems in this experimental section contained the same amounts of BHT and $\beta$-carotene/linoleic acid emulsion but different amounts of methanol (see Table 1 for clarity). The dependence presented in Fig. 3 proves that the increase in the antioxidant solvent volume decreases the inhibition percent. The observed changes are difficult to explain in an unequivocal way. However, the increase in methanol concentration in the measuring system leads to the changes in system viscosity and solubility of its components, all of which can be responsible for the BHT \% inhibition decrease. Thus, the volume ratio of the examined antioxidant solution to $\beta$ carotene/linoleic acid emulsion significantly influences the activity estimation of antioxidant properties.

The presence of natural acids in plant extracts is rarely taken into consideration when comparing the antioxidant properties of these extracts. Plant extracts can differ quantitatively and qualitatively not only in the composition of antioxidants but also in natural acids, which makes their $\mathrm{pH}$ different, too. Moreover, investigators frequently apply extrahents of different $\mathrm{pH}$ to isolate examined components

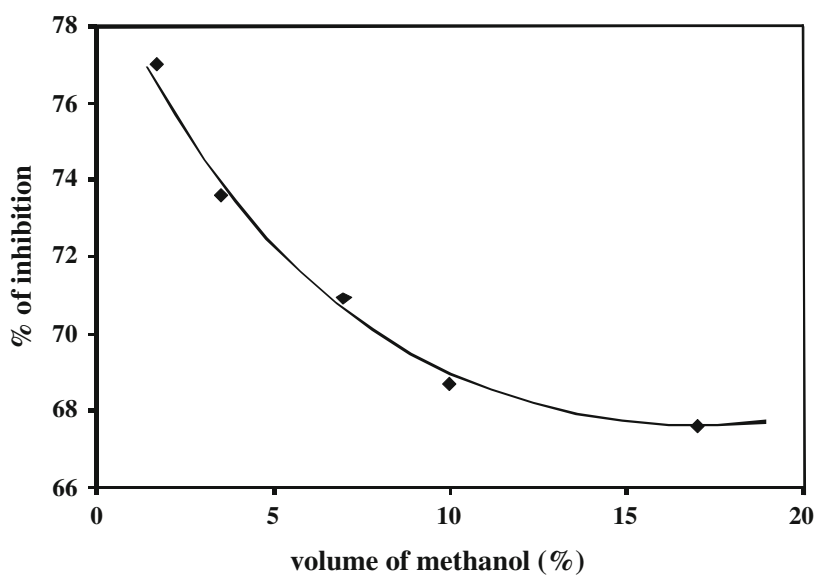

Fig. 3 The influence of methanol volume (BHT solvent) on antioxidant activity percent of BHT after $180 \mathrm{~min}$ of the reaction

from plant matrices. Figure 4 illustrates the influence of $\mathrm{pH}$ on the difference $(\Delta)$ between the inhibition percent of the buffered sample in relation to the control and inhibition percent of the non-buffered sample in relation to the control, after $180 \mathrm{~min}$ of the reaction. As results from the figure, the elevated hydrogen ion concentration produces an elevated but an almost constant estimated value of the BHT antioxidant activity (positive $\Delta$ ). The observed increase in BHT antioxidant activity at lower $\mathrm{pH}$ is in agreement with results by Valgimigli et al. [13] who reports that the presence of small amounts of acid leads to an acceleration of the rate reactions between phenols and chain-carrying peroxyl radicals. As appears from Fig. 4, the increase in $\mathrm{pH}$ above $4.15 \mathrm{pH}$ unit results in the decrease in $\Delta$ toward negative values. It looks as if the $\mathrm{pH}$ increase resulted in the increase in $\beta$-carotene depletion or the additional formation of peroxyl radical in the examined system during the experiment. Although these explanations require further investigation, they seem less likely. The

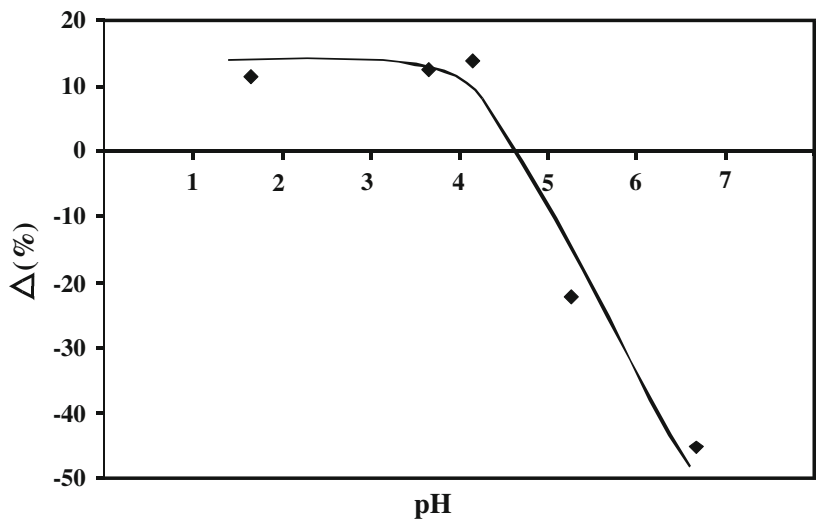

Fig. 4 The influence of $\mathrm{pH}$ on the difference $(\Delta)$ between antioxidant activity percent of BHT in buffered and non-buffered sample, after $180 \mathrm{~min}$ of the reaction 
influence of $\mathrm{pH}$ on BHT dissociation degree in the examined $\mathrm{pH}$ range also seems less convincing as an explanation of the observed relationship (see Fig. 4) as $p \mathrm{~K}_{\mathrm{a}}$ of this compound equals 12.2 [18]. The significance of $\mathrm{pH}$ is additionally presented in the work of Junatochote and Berghofer [19], who showed the opposite influence of $\mathrm{pH}$ on antioxidative activity of some essential oils, i.e. that $\mathrm{pH}$ increase intensifies the antioxidant activity of essential oils. Thus, the influence of $\mathrm{pH}$ on antioxidant activity of compounds needs further consideration.

The presence of metal ions in plant extracts is a consequence of their natural existence in plants. Their concentration in such extracts is different and depends on many factors such as plant type, plant growing conditions (including soil pollution by metals), ion type, extrahent type and extracting conditions. The influence of the concentration of some metal ions on the difference $(\Delta)$ between inhibition percent of the sample polluted with metal ion in relation to the control and inhibition percent of the sample free of metal ion in relation to the control, after $180 \mathrm{~min}$ of the reaction, is illustrated in Fig. 5. The presented dependences are limited to $\mathrm{Fe}(\mathrm{III}), \mathrm{Cu}$ (II) and $\mathrm{Zn}$ (II) concentration probable in plant extracts, assuming that the whole amount of a given metal ion is extracted from $1 \mathrm{~g}$ of plant sample to $50 \mathrm{~mL}$ of extrahent. As results from the plots in Fig. 5, the increase in metal ion concentration in the examined concentration range causes a linear decrease in the estimated inhibition percent (negative $\Delta$ ). According to Bendich, Machalin, Scandura, Burton and Wayner [20], the presence of some transition metal ions results in autoxidative destruction of vitamin $\mathrm{C}$, which promotes and accelerates the autoxidation of polyunsaturated lipid material. It is difficult to explain the inhibition percent

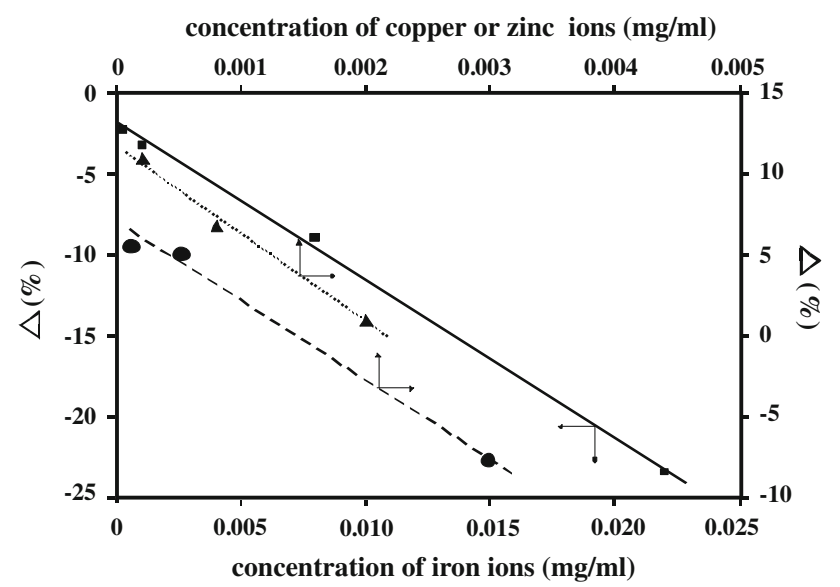

Fig. 5 The influence of metal ion concentration [solid line with squares for $\mathrm{Fe}(\mathrm{III})$, dashed line with circles for $\mathrm{Cu}(\mathrm{II})$ and dotted line with triangles for $\mathrm{Zn}(\mathrm{II})]$ on the difference $(\Delta)$ between antioxidant activity percent of BHT in sample with and without metal ions. For details concerning measuring system, see "Experimental" decline of BHT resulting from the presence of metal ions in the system by the destruction of the antioxidant (BHT) used in the experiments. The relationships in Fig. 5 show that the increase in metal ion concentration accelerates the oxidation process in the examined systems. It is in agreement with the literature [21-23],which reports that the presence of metal ions [e.g. $\mathrm{Cu}(\mathrm{II}), \mathrm{Zn}(\mathrm{II}), \mathrm{Ni}(\mathrm{II})$, and $\mathrm{Mn}(\mathrm{II})]$ induces lipid oxidation. The relationships from Fig. 5 can also be explained assuming that hydroperoxides $(\mathrm{LOOH})$ composed during reaction of an antioxidant with peroxyl radicals are, due to the presence of the metal ion, disintegrated back to the formation of peroxyl radicals [24]. It seems to be less probable in the case of $\mathrm{Zn}$ (II) as the decomposition process is catalyzed by redox active transition metal ions [e.g. $\mathrm{Cu}$ (II) or $\mathrm{Fe}(\mathrm{III})$ ].

\section{Conclusions}

The $\beta$-carotene bleaching assay belongs to the oldest methods employed for estimating antioxidant activity. However, the review of the publications concerning this method revealed that different protocols of the method are used. Moreover, researchers seldom pay attention to factors influencing the estimation of antioxidant activity of the examined compounds or mixtures. The paper shows that factors such as the antioxidant solvent type, the volume ratio of antioxidant solution to $\beta$-carotene/linoleic acid water emulsion, metal content and $\mathrm{pH}$ have the essential influence on the concentration of unreacted $\beta$-carotene and are responsible for difference in the estimation of antioxidant activity. The presented results indicated the difficulty in the estimation of true antioxidant properties of food components, plant extracts or even antioxidant additives preventing products from oxidative changes.

There are many statements in literature pointing the necessity of DPPH method standardization [25]. The results presented in this paper show that it is also the $\beta$ carotene method that needs standardization.

Open Access This article is distributed under the terms of the Creative Commons Attribution Noncommercial License which permits any noncommercial use, distribution, and reproduction in any medium, provided the original author(s) and source are credited.

\section{References}

1. Halliwell B (1992) Reactive oxygen species and the central nervous system. J Neurochem 59:1609-1623

2. Aruoma OI (1998) Free radicals, oxidative stress, and antioxidants in human health and disease. J Am Oil Chem Soc 75:199-212

3. McCord JM (2000) The evolution of free radicals and oxidative stress. Am J Med 108:652-659 
4. Scalbert A, Manach C, Morand C, Remsy C (2005) Dietary of polyphenols and the prevention of diseases. Crit Rev Food Sci Nutr 45:287-306

5. Moon J, Shibamoto T (2009) Antioxidant assays for plant and food components. J Agric Food Chem 57:1655-1660

6. Lee Y, Howard LR, Villalón B (1995) Flavonoids and antioxidant activity of fresh pepper (Capsicum annuum) cultivars. J Food Sci 60:473-476

7. Ismail A, Marjan ZM, Foong CW (2004) Total antioxidant activity and phenolic content in selected vegetables. Food Chem 87:581-586

8. Tepe B, Daferera D, Sokmen A, Sokmen M, Polissiou M (2005) Antimicrobial and antioxidant activities of essential oil and various extracts of Salvia tomentosa Miller (Lamiaceae). Food Chem 90:333-340

9. Dawidowicz AL, Wianowska D, Baraniak B (2006) The antioxidant properties of alcoholic extracts from Sambucus nigra L. (antioxidant properties of extracts). LWT Food Sci Technol 39:308-315

10. Gulluc M, Sahin F, Sokmen M, Ozer H, Daferera D, Sokmen A, Polissiou M, Adiguzel A, Ozkan H (2007) Antimicrobial and antioxidant properties of the essential oils and methanol extract from Mentha longfolia L. ssp. Longifolia. Food Chem 103:1449-1456

11. El-Agamey A, Lowe GM, McGarvey DJ, Mortensen A, Phillip DM, Truscott TG, Young AJ (2004) Carotenoid radical chemistry and antioxidant/pro-oxidant properties. Arch Biochem Biophys 430:37-48

12. Miller NJ, Sampson J, Candeias LP, Bramley PM, Rice-Evans C (1996) Antioxidant activities of carotenes and xanthophylls. FEBS Letters 384:240-242

13. Valgimigli L, Amorati R, Petrucci S, Peduli GF, Hu D, Hanthorn JJ, Pratt DA (2009) Unexpected acid catalysis in reaction of peroxyl radicals with phenols. Angew Chem Int Ed 48: $8348-8351$
14. Litwinienko G, Ingold KU (2003) Abnormal solvent effects on hydrogen atom abstraction. 1. The reactions of phenols with 2,2diphenyl-1-picrylhydrazyl (dpph) in alcohols. J Org Chem 68:3433-3438

15. Kamlet MJ, Abboud JLM, Abraham MH, Taft RW (1983) Linear salvation energy relationships. 23. A comprehensive collection of the solvatochromic parameters,pi.*,alpha., and.beta., and some methods for simplifying the generalized solvatochromic equation. J Org Chem 48:2877-2887

16. Litwinienko G, Ingold KU (2004) Abnormal solvent effects on hydrogen atom abstraction. 2. Resolution of the curcumin antioxidant controversy. The role of sequential proton loss electron transfer. J Org Chem 69:5888-5896

17. Barton AFM (1983) CRC Press, pp 153-157

18. Musialik M, Litwinienko G (2005) Scavenging of dpph radicals by vitamin $\mathrm{E}$ is accelerated by its partial ionization: the role of sequential proton loss electron transfer. Org Lett 7:4951-4954

19. Junatachote T, Berghofer E (2005) Antioxidative properties and stability of ethanolic extracts of Holy basil and Galangal. Food Chem 92:193-202

20. Bendich A, Machalin LJ, Scandura O, Burton GW, Wayner DDM (1986) The antioxidant role of vitamin C. Adv Free Radical Biol Med 2:419-444

21. Laguerre M, Lecomte J, Villeneuve P (2007) Evaluation of the ability of antioxidants to counteract lipid oxidation: Existing methods, new trends and challenges. Prog Lipid Res 46:244-282

22. Frankel EN (1984) Lipids oxidation: mechanism, product and biological significance. J Am Oil Chem Soc 61:1908-1917

23. Ramanathan L, Das NP (1992) Inhibitory effects of some natural products on metal-induced lipid oxidation in cooked fish. Biol Trace Elem Res 34:35-44

24. Hawkins CL, Davies MJ (2001) Generation and propagation of radical reactions on proteins. Biochim Biophys Acta 1504:196-219

25. Sharma OP, Bhat TK (2009) DPPH antioxidant assay revisited. Food Chem 113:1202-1205 